\title{
Chaotic Behavior in a Dynamic Love Model with Different External Forces
}

\section{Youngchul Bae}

Department of Electrical and Semiconductor Engineering, Chonnam National University, Yeosu, Korea

\section{]jfis}

\begin{abstract}
In this paper, we propose a dynamic mathematical model of love involving various external forces, in order to analyze the chaotic phenomena in a love model based on Romeo and Juliet. In addition, we investigate the nonlinear phenomena in a love model with external forces using time series and phase portraits. In order to describe nonlinear phenomena precisely using time series and phase portraits, we vary the type of external force, using models such as a sine wave, chopping wave, and square wave. We also apply various different parameters in the Romeo and Juliet model to acquire chaotic dynamics.
\end{abstract}

Keywords: Chaotic phenomena, Nonlinear dynamic, Love model, Time series, Phase portrait, External force

\section{Introduction}

As the world inhabited by humans is organized into complex systems, human society can also be described as a complex system. A complex system is an example of a nonlinear dynamical system. It is well known that nonlinear systems are difficult to analyze, synthesize, or implement in comparison with linear systems.

All systems that naturally occur are nonlinear in nature. Furthermore, all kinds of phenomena that are modeled by fuzzy neural networks, chaotic systems, and complex systems correspond to systems that are nonlinear. During recent decades, the analysis and applications of chaotic phenomena in nonlinear systems has been widely researched in connection with fields including natural sciences, engineering, psychology, and social sciences [1-7].

Received: Dec. 9, 2015

Revised : Dec. 24, 2015

Accepted: Dec. 25, 2015

Correspondence to: Youngchul Bae (ycbae@chonnam.ac.kr)

(CThe Korean Institute of Intelligent Systems

cCThis is an Open Access article distributed under the terms of the Creative Commons Attribution Non-Commercial License (http://creativecommons.org/licenses/ by-nc/3.0// which permits unrestricted noncommercial use, distribution, and reproduction in any medium, provided the original work is properly cited.

Recently, some researchers have been interested in models for addiction [8-11], happiness [12-15], and love [15-20], which involve an overlap of mathematics, biology, psychology, and social science.

Bae [8-10] and Bae and Kim [11] proposed a mathematical model for addictions to digital leisure, internet use, tobacco use, and physical exercise. He also confirmed the presence of nonlinear or chaotic phenomena, using time series and phase portraits. Sprott [13, 15] proposed a basic dynamic equation for happiness, and investigated its behavior. Kim et al. [12] and Bae [14] proposed a mathematical happiness model and a synchronization technique for the model.

Several models have been proposed for love, such as the Romeo and Juliet model [13, 15], the Laura and Petrarch model [21], and the Adam and Eve model [22]. Among these, the love model based on Romeo and Juliet is most commonly employed in the study of nonlinear dynamics. 
Sprott [15] first proposed a love model based on Romeo and Juliet using a linear differential equation, and he also described both the linear and nonlinear behavior of the model. The existence of periodic and chaotic behavior in the love model based on Romeo and Juliet is represented through time series and phase portraits, with either the same or different time delays, and an external force proposed by Bae and his colleagues [1620]. However, the majority of previously published papers have not provided an exact time series or phase portrait for demonstrating chaotic phenomena in the Romeo and Juliet model. In order to analyze such chaotic behavior, we should formulate a dynamic mathematical model using ordinary differential equations or difference equations, following the models of addiction, happiness, and love.

In this paper, we propose a dynamic mathematical model of love with various external forces. We also investigate the nonlinear phenomena present in love models with external forces using time series and phase portraits. In order to describe the nonlinear phenomena precisely using time series and phase portraits, we vary the type of external force, using models such as a sine wave, chopping wave, and square wave. We also apply various parameters in the Romeo and Juliet model to acquire chaotic dynamics.

\subsection{Basic Love Model}

The basic love model proposed by Sprott [15] can be formulated by the equations

$$
\begin{aligned}
& \frac{\mathrm{dR}}{\mathrm{dt}}=\mathrm{aR}+\mathrm{bJ}, \\
& \frac{\mathrm{dJ}}{\mathrm{dt}}=\mathrm{cR}+\mathrm{dJ},
\end{aligned}
$$

where a and b specify Romeo's romantic style and c and d specify Juliet's style.

\subsection{Alternative Love Model}

An alternative love model, also proposed by Sprott [15], can be written as

$$
\begin{aligned}
& \frac{\mathrm{dR}}{\mathrm{dt}}=\mathrm{aR}+\mathrm{bJ}(1-|\mathrm{J}|), \\
& \frac{\mathrm{dJ}}{\mathrm{dt}}=\mathrm{cR}(1-|\mathrm{R}|)+\mathrm{dJ},
\end{aligned}
$$

where a and b specify Romeo's romantic style and c and d specify Juliet's style.

\subsection{Alternative Love Model with an External Force}

Eqs. (1) and (2) cannot be used to model chaotic phenomena, because these are only second-order systems. In order to generate chaotic phenomena in the dynamic model, the love model must involve a third-order system, and must also contain at least one nonlinear term. Because Eqs. (1) and (2) do not satisfy the necessary conditions, they must be modified in order to generate chaotic phenomena. An alternative love model proposed by Bae et al. [16], involving external forces, can be written as

$$
\begin{aligned}
& \frac{\mathrm{dR}}{\mathrm{dt}}=\mathrm{aR}+\mathrm{bJ}(1-|\mathrm{J}|)+f(t), \\
& \frac{\mathrm{dJ}}{\mathrm{dt}}=\mathrm{cR}(1-|\mathrm{R}|+\mathrm{d} \mathrm{J}+\mathrm{y}(\mathrm{t}),
\end{aligned}
$$

where $f(t)$ and $y(t)$ are external forces.

Kim et al. [16] and Bae [17, 18] demonstrated the existence of chaotic phenomena when $f(t)=\sin \omega t$ and $y(t)=0$ in Eq (3), using phase portraits of periodic doubling and a chaotic attractor.

\section{Analysis of Chaotic Phenomena in an Alter- native Love Model with Different External Forces}

In this paper, we investigate the chaotic phenomena occurring in Eq. (3) for various different external forces, including sine waves, chopping waves, and square waves, using computer simulation with MATLAB. In addition, we apply different parameters for the Romeo and Juliet model.

\subsection{Case $a=-2, b=-2, c=1, d=1$}

We investigate the time series and chaotic attractor to discover the nature of chaotic phenomena when we fix the parameters as a $=-2, \mathrm{~b}=-2, \mathrm{c}=1$, and $\mathrm{d}=1$. We also apply different external forces, with $\mathrm{y}(\mathrm{t})=\sin \omega \mathrm{t}$ and $\mathrm{f}(\mathrm{t})=\operatorname{triplus}(\mathrm{t}, \mathrm{w})$ with $\mathrm{w}=100$ for Romeo and Juliet, respectively. In this case, we can consider that the external forces applied for Romeo and Juliet are completely different. This means that different people are modeled by Romeo and Juliet, who have different ways of thinking and opinions.

Figure 1 illustrates the results of the time series and phase portrait when we apply these different external forces for Romeo and Juliet. 


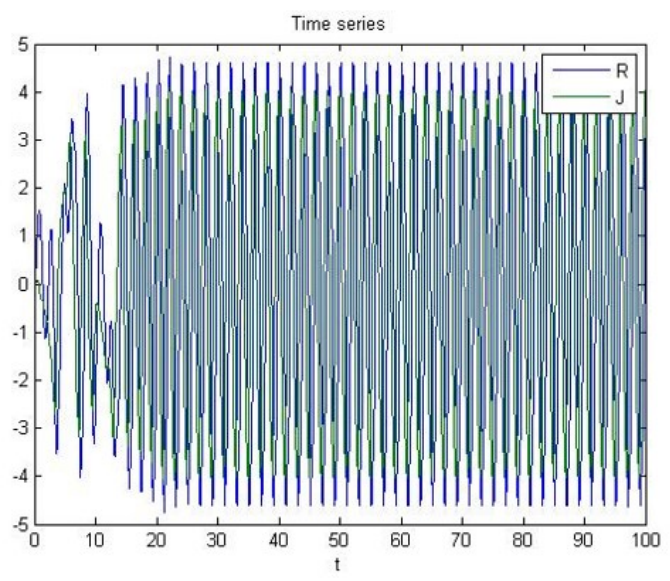

(a)

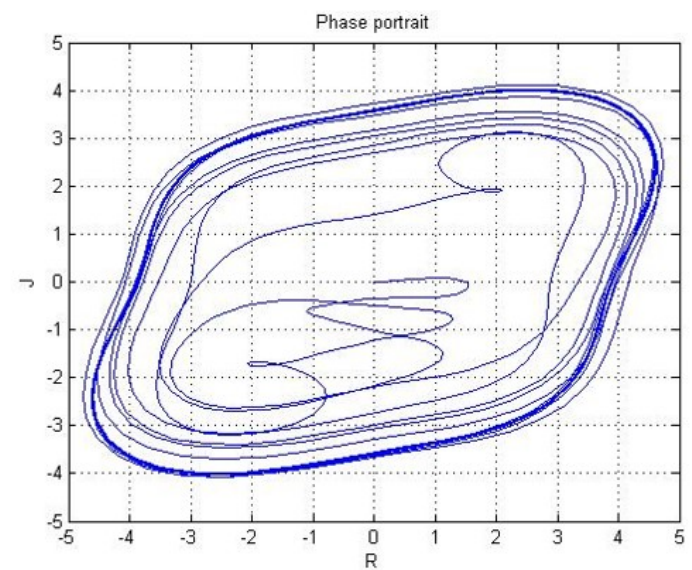

(b)

Figure 1. Results of the time series (a) and phase portrait (b) when we apply the external forces as $\mathrm{y}(\mathrm{t})=\sin \omega \mathrm{t}$ and $\mathrm{f}(\mathrm{t})=\operatorname{triplus}(\mathrm{t}, \mathrm{w})$, $\mathrm{w}=100$, with $\mathrm{a}=-2, \mathrm{~b}=-2, \mathrm{c}=1$, and $\mathrm{d}=1$.

\subsection{Case $a=-2, b=-2, c=1, d=1$}

We now investigate the chaotic attractor to discover the nature of the chaotic phenomena when we fix the parameters as a $=$ $-2, \mathrm{~b}=-2, \mathrm{c}=1$, and $\mathrm{d}=1$. We also apply different external forces, with $\mathrm{y}(\mathrm{t})=\sin \omega \mathrm{t}$ and $\mathrm{f}(\mathrm{t})=\operatorname{rectplus}(\mathrm{t}, \mathrm{w})$ with $\mathrm{w}=100$ for Romeo and Juliet, respectively. Figure 2 illustrates the results of the time series and phase portrait with such parameters.

\subsection{Case $a=-3, b=-2, c=1, d=1$}

We now investigate the chaotic attractor to discover the nature of the chaotic phenomena when we fix the parameters as $\mathrm{a}=-3, \mathrm{~b}=-2, \mathrm{c}=1$, and $\mathrm{d}=1$. We also apply differ-

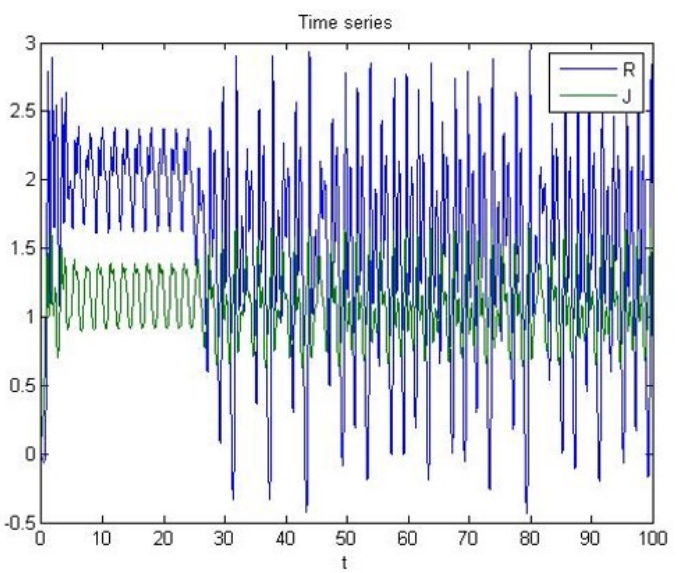

(a)

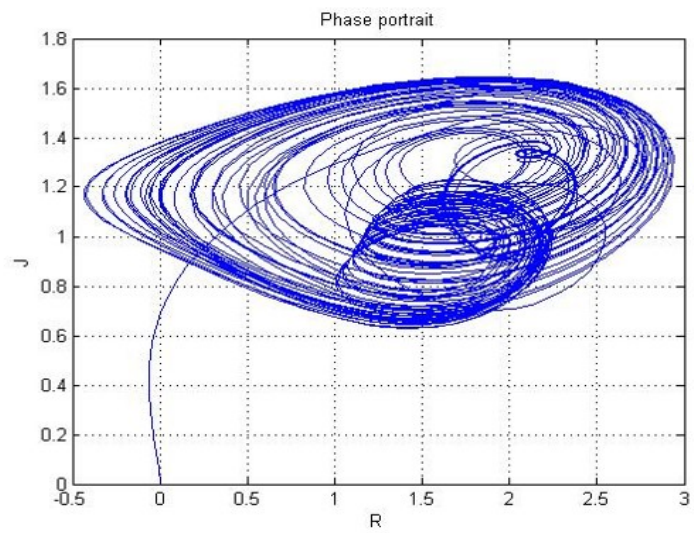

(b)

Figure 2. Results of the time series (a) and phase portrait (b) when we apply the external forces as $\mathrm{y}(\mathrm{t})=\sin \omega \mathrm{t}$ and $\mathrm{f}(\mathrm{t})=\operatorname{rectplus}(\mathrm{t}, \mathrm{w})$, $\mathrm{w}=100$, with $\mathrm{a}=-2, \mathrm{~b}=-2, \mathrm{c}=1$, and $\mathrm{d}=1$.

ent external forces, with $\mathrm{y}(\mathrm{t})=\sin \omega \mathrm{t}$ and $\mathrm{f}(\mathrm{t})=$ square $(\mathrm{t}, \mathrm{w})$ with $\mathrm{w}=50$ for Romeo and Juliet, respectively. Figure 3 illustrates the results of the time series and phase portrait with these parameters.

By comparing Figures 1-3, we recognize that there is a notable difference when we vary the external force $f(t)$. This indicates that the status of love between Romeo and Juliet can be affected by external forces such as the opinions of parents, friends, and other family members.

\subsection{Case $a=-3, b=-2, c=1, d=1$}

Now, we investigate the chaotic attractor to discover the nature of the chaotic phenomena when we fix the parameters as a $=$ $-3, \mathrm{~b}=-2, \mathrm{c}=1$, and $\mathrm{d}=1$. We also apply different external forces, with $\mathrm{y}(\mathrm{t})=\sin \omega \mathrm{t}$ and $\mathrm{f}(\mathrm{t})=\operatorname{rectplus}(\mathrm{t}, \mathrm{w})$ 


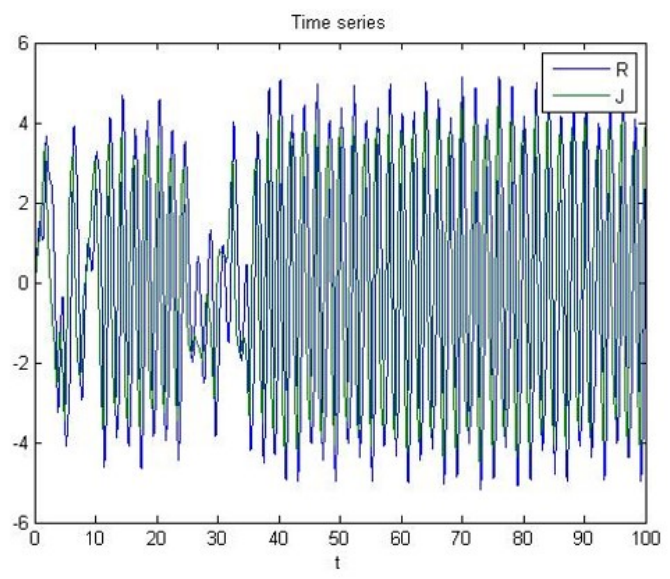

(a)

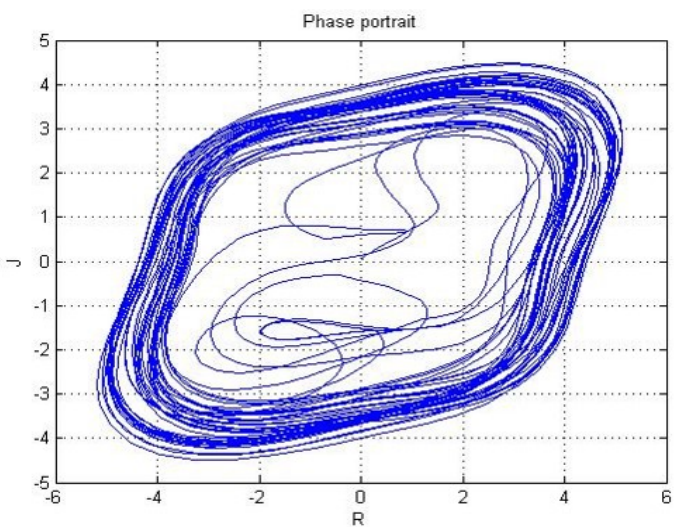

(b)

Figure 3. Results of the time series (a) and phase portrait (b) when we apply the external forces as $\mathrm{y}(\mathrm{t})=\sin \omega \mathrm{t}$ and $\mathrm{f}(\mathrm{t})=\operatorname{square}(\mathrm{t}, \mathrm{w})$, $\mathrm{w}=50$, with $\mathrm{a}=-3, \mathrm{~b}=-2, \mathrm{c}=1$, and $\mathrm{d}=1$.

with $\mathrm{w}=100$ for Romeo and Juliet, respectively. Figure 4 illustrates the results of the time series and phase portrait with these parameters.

By comparing Figures 1 and 4, we can see that there is a clear difference when we vary the parameter a. This means that intensity of love between Romeo and Juliet can vary according to the personality of Romeo. From this result, we infer that the status of love between Romeo and Juliet can be affected by the parameter settings of a, b, c, and d, which represent the states of mind of both participants.

\subsection{Case $a=-3, b=-2, c=1, d=1$}

We now investigate the chaotic attractor to discover the nature of the chaotic phenomena when we fix the parameters as a $=$ $-3, \mathrm{~b}=-11, \mathrm{c}=1$, and $\mathrm{d}=1$. We also apply different

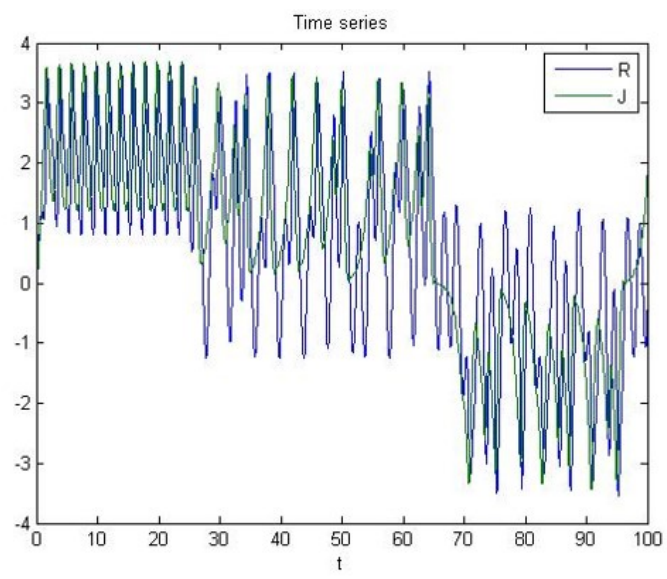

(a)

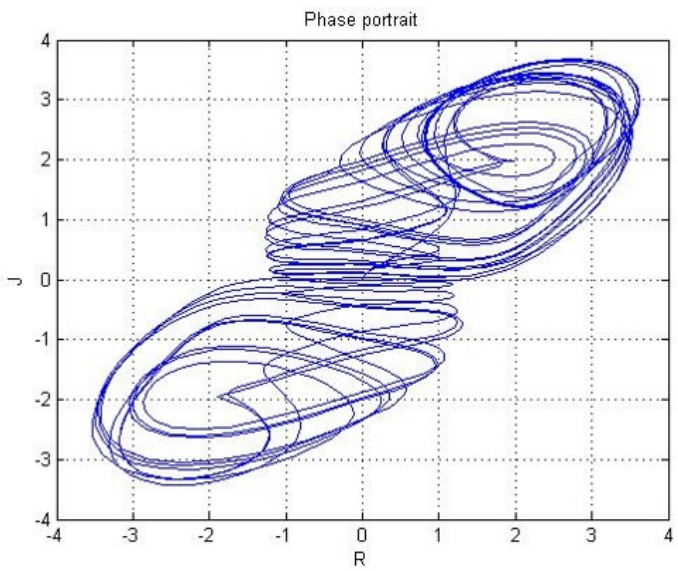

(b)

Figure 4. Results of the time series (a) and phase portrait (b) when we apply the external forces as $\mathrm{y}(\mathrm{t})=\sin \omega \mathrm{t}$ and $\mathrm{f}(\mathrm{t})=\operatorname{triplus}(\mathrm{t}, \mathrm{w})$, $\mathrm{w}=100$, with $\mathrm{a}=-3, \mathrm{~b}=-2, \mathrm{c}=1$, and $\mathrm{d}=1$.

external forces, with $\mathrm{y}(\mathrm{t})=\operatorname{triplus}(\mathrm{t}, \mathrm{w})$ with $\mathrm{w}=50$ and $\mathrm{f}(\mathrm{t})=$ square $(\mathrm{t}, \mathrm{w})$ with $\mathrm{w}=100$ for Romeo and Juliet, respectively. Figure 5 illustrates the results of the time series and phase portrait with these parameters.

By comparing Figures 1 and 5, we recognize that there is a clear difference when we vary both the parameters and the external forces. Therefore, we conjecture that the love between Romeo and Juliet is affected by many factors, including their own states of mind and current circumstances. Hence, in order to maintain a relationship between a man and woman, both should give their best efforts to maintain their love status. 


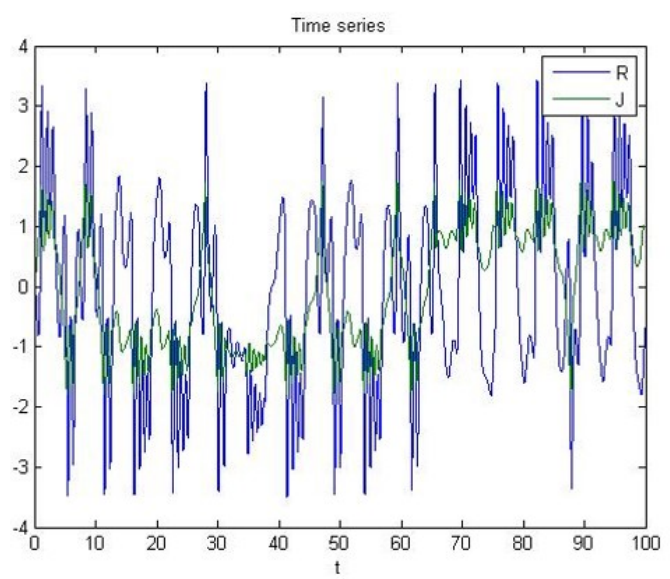

(a)

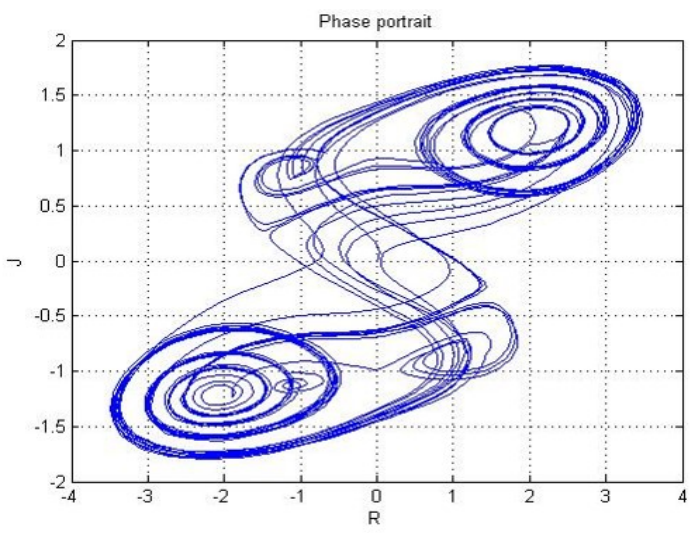

(b)

Figure 5. Results of the time series (a) and phase portrait (b) when we apply the external forces as $\mathrm{y}(\mathrm{t})=\operatorname{tripius}(\mathrm{t}, \mathrm{w}), \mathrm{w}=50$, and $\mathrm{f}(\mathrm{t})=$ square $(\mathrm{t}, \mathrm{w}), \mathrm{w}=100$, with $\mathrm{a}=-3, \mathrm{~b}=-2, \mathrm{c}=1$, and $\mathrm{d}=1$.

\section{Conclusions and Remarks}

In this paper, we have proposed a dynamic mathematical model of love, involving different external forces. Furthermore, we investigated the chaotic phenomena occurring in a love model with external forces using time series and phase portraits.

From the time series and phase portraits that we acquired using computer simulation, we were able to recognize two important facts. First, we recognize that there is a clear difference in the results as the external force $\mathrm{f}(\mathrm{t})$ is varied. This implies that the status of love between Romeo and Juliet can be affected by external forces such as the opinions of parents, friends, and other family members. Second, there is a clear difference in the results in cases where both the parameters and external forces are changed. Therefore, we conjecture that the love between
Romeo and Juliet is affected by many factors, such as their own states of mind and present circumstances. Hence, in order to maintain a relationship between a man and woman, both should give their best efforts to maintain their love status.

\section{Conflict of Interest}

No potential conflict of interest relevant to this article was reported.

\section{Acknowledgements}

The author wishes to acknowledge that the research is done as a part of BK21 Plus Center for Training Top-Level Human Resources in Future Fusion Bio Electronic Medical Technology in Chonnam National University made in the program year 2014.

\section{References}

[1] S. H. Yu, C. H. Hyun, and M. Park, "Backstepping control and synchronization for 4-D Lorenz-Stenflo chaotic system with single input," International Journal of Fuzzy Logic and Intelligent Systems, vol. 11, no. 3, pp. 143-148, 2011. http://dx.doi.org/10.5391/IJFIS.2011.11.3.143

[2] S. H. Yu, C. H. Hyun, and M. Park, "Control and synchronization of new hyperchaotic system using active backstepping design," International Journal of Fuzzy Logic and Intelligent Systems, vol. 11, no. 2, pp. 77-83, 2011. http://dx.doi.org/10.5391/IJFIS.2011.11.2.077

[3] Y. C. Bae, "Diagnosis of power supply by analysis of chaotic nonlinear dynamics," Journal of the Korea Institute of Electronic Communication Sciences, vol. 8, no. 1, pp. 113-119, 2013. http://dx.doi.org/10.13067/JKIECS 2013.8.1.113

[4] Y. C. Bae, "Chaotic phenomena in MEMS with duffing equation," Journal of the Korea Institute of Electronic Communication Sciences, vol. 6, no. 5, pp. 709-716, 2011.

[5] Y. C. Bae and J. K. Park "A study on obstacle avoid method and synchronization of multi chaotic robot for robot formation control based on chaotic theory," Journal of the Korea Institute of Electronic Communication Sciences, vol. 5, no. 5, pp. 534-540, 2010.

[6] Y. C. Bae, "A study on chaotic phenomenon in rolling mill bearing," Journal of Korean Institute of Intelligent Systems, vol. 11, no. 4, pp. 315-319, 2001. 
[7] Y. C. Bae, J. W. Kim, Y. G. Kim, and Y. W. Shon, "Secure communication using embedding drive synchronization," Journal of Korean Institute of Intelligent Systems, vol. 13, no. 3, pp. 310-315, 2003.

[8] Y. C. Bae, "Chaotic phenomena in addiction model for digital leisure," International Journal of Fuzzy Logic and Intelligent Systems, vol. 13, no. 4, pp. 291-297, 2013. http://dx.doi.org/10.5391/IJFIS.2013.13.4.291

[9] Y. C. Bae, "Chaotic dynamics in tobacco's addiction model," International Journal of Fuzzy Logic and Intelligent Systems, vol. 14, no. 4, pp. 322-331, 2014. http://dx.doi.org/10.5391/IJFIS.2014.14.4.322

[10] Y. C. Bae, "Mathematical modelling and behavior analysis of addiction of physical exercise," Journal of Korean Institute of Intelligent Systems, vol. 24, no. 6, pp. 615-621, 2014. http://dx.doi.org/10.5391/JKIIS.2014.24.6.615

[11] M. M. Kim and Y. C. Bae, "Mathematical modelling and chaotic behavior analysis of cyber addiction," Journal of Korean Institute of Intelligent Systems, vol. 24, no. 3, pp. 245-250. 2014. http://dx.doi.org/10.5391/JKIIS.2014.24. 3.245

[12] S. W. Kim, S. K. Choi, Y. C. Bae, and Y. H. Park, "Mathematical modelling of happiness and its nonlinear analysis," Journal of the Korea Institute of Electronic Communication Science, vol. 9, no. 6, pp. 711-717, 2013. http://dx.doi.org/10.13067/JKIECS.2014.9.6.711

[13] J. C. Sprott, "Dynamical models of happiness," Nonlinear Dynamics, Psychology, and Life Sciences, vol. 9, no. 1, pp. 23-34, 2005.

[14] Y. Bae, "Synchronization of dynamical happiness model," International Journal of Fuzzy Logic and Intelligent Systems, vol. 14, no. 2, pp. 91-97, 2014. http://dx.doi.org/10. 5391/IJFIS.2014.14.2.91

[15] J. C. Sprott, "Dynamics of love and happiness," presented at the Chaos and Complex Systems Seminar, Madison, WI, 2001.

[16] S. W. Kim, Y. W. Shon and Y. C. Bae, "Mathematical modelling of love and its nonlinear analysis," Journal of the Korea Institute of Electronic Communication Sciences, vol. 9, no. 11, pp. 1297-1303, 2014. http://dx.doi.org/10. 13067/JKIECS.2014.9.11.1297

[17] Y. C. Bae, "Behavior analysis of dynamic love model with time delay," Journal of the Korea Institute of Electronic
Communication Sciences, vol. 10, no. 2, pp. 253-260, 2015. http://dx.doi.org/10.13067/JKIECS.2015.10.2.253

[18] Y. C. Bae, "Modified mathematical modelling of love and its behaviour analysis," Journal of the Korea Institute of Electronic Communication Sciences, vol. 9, no. 12, pp. 1441-1446, 2014. http://dx.doi.org/10.13067/JKIECS. 2014.9.12.1441

[19] L. Huang and Y. C. Bae, "Behavior analysis in love model of Romeo and Juliet with time delay," Journal of Korean Institute of Intelligent Systems, vol. 25, no. 2, pp. 155-160, 2015. http://dx.doi.org/10.5391/JKIIS.2015.25.2.155

[20] L. Huang and Y. C. Bae, "Comparative behavior analysis in love model with same and different time delay," Journal of Korean Institute of Intelligent Systems, vol. 25, no. 3, pp. 210-216, 2015. http://dx.doi.org/10.5391/JKIIS.2015. 25.3.210

[21] F. Breitenecker, F. Judex, N. Popper, K. Breitenecker, A. Mathe, and A. Mathe, "Love emotions between Laura and Petrarch: an approach by mathematics and system dynamics," Journal of Computing and Information Technology - CIT, vol. 16, no. 4, pp. 255-269, 2008. http://dx.doi.org/10.2498/cit.1001393

[22] J. M. Rey, "Optimal control of long-term sentimental dynamics," in Proceedings of Modelling for Engineering \& Human Behavior 2011, Valencia, Spain, 2011, pp. 274278.

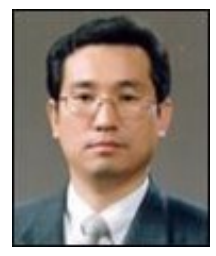

Youngchul Bae received his B.S., M.S., and Ph.D. from the Department of Electrical Engineering, Kwangwoon University, Korea, in 1984, 1985, and 1997, respectively. He worked at KEPCO (Korea Electric Power Company) during 1986-1991, and also worked at KISTI (Korea Institute of Science and Technology Information) during 1991-1997 as a senior researcher. He is currently professor at the Division of Electrical and Electronic Communication and Computer Engineering, Chonnam National University, Yeosu, Korea. His research interests include nonlinear dynamics, chaos dynamics, robot control, intelligent system and motor control. $\mathrm{He}$ is member of KIEE, KIECS and KIIS.

Tel: +82-61-659-7315, Fax: +82-61-659-7310

E-mail: ycbae@chonnam.ac.kr 